\title{
Innovative Teaching: Spiritual Care And Information Processing
}

\author{
${ }^{1 s t}$ Henie Kurniawati \\ Fakultas Psikologi \\ Universitas Gadjah Mada \\ Yogyakarta, Indonesia \\ henie.jurnia@gmail.com
}

\author{
${ }^{2 n d}$ Sofia Retnowati \\ Fakultas Psikologi \\ Universitas Gadjah Mada \\ Sofi_53@ugm.ac.id
}

\author{
${ }^{3 e d}$ Bagus Riyono \\ Fakultas Psikologi \\ Universitas Gadjah Mada \\ bagus@ugm.ac.id
}

\author{
${ }^{4 \text { th }}$ Widyawati \\ Fakultas Psikologi \\ Universitas Gadjah Mada \\ Widyawati.poernomo@ugm. \\ ac.id
}

\begin{abstract}
Introduction: innovative teaching combinesspritual care and information processing. Objective: reviewing references related to information processing and spiritual care. Method:review for teaching methods and practices affecting the spiritual care process. Review and conclusions: human behavior is determined by internal information processing and doingaconsistent spiritual care. Innovative teaching should integrate the cognition and spirituality by habituating or implementing spritual care and human information processing.
\end{abstract}

Keywords: innovative teaching, spiritual care, information processing

\section{INTRODUCTION}

Overview of the information processing system has two cognitive system characteristics that are always held by any theorists and cognitive and clinical practitioners, namely: (1) that human thinking capacity has certain limitations, both in terms of the amount of information that can be absorbed and the speed information processing that can be done. (2) that the ability to think is flexible; the capability to adapt changes in goals, circumstances, and assignment demands that continue to occur constantly with the basic recognition and application of spiritual care that underlies human cognition (Wickens, 2000)

There are several important assumptions held by researchers and practicioners who adopt an information processing and spiritual approach to innovative teaching. The most important assumption is that behavior is determined by the spiritual basis and cognition in the form of internal information processing in a person. Some researchers use psychophysiological and spirituality measurements such as brain waves to help explain this black block, as this technique cannot be used as hypothetical information for now (Wickens, 2000).

Human behavior is determined by internal information flow and spiritual basis. Information flow cannot be observed directly, it must be concluded instead. Many innovative teaching techniques try to map internal and spiritual information pathways. When most researchers and practicioners agree on the goodness of certain models, then the agreement must be able to follow rapid progress (or at least it can be said to be a rapid change) in the teaching of information processing that has been "agreed" especially dealing with human factors to continuously follow the latest innovative findings (Kantowitz \& Sorkin1983).

Education and overall health are interrelated. A condition about physical appearance (biological), intellectual (ratio / cognitive), emotional (affective) and spiritual (spirituality) must be optimal sothat they can runin harmony with social interaction. This is a particular challenge for education and effective care for students who experience health problems, such as somatization while studying (Timmer,Bleicardt\& Rief, 2006).

\section{METHODS}

This study uses a review method. The method involves a critical review in the selection of topics, and the results are communicated. Review is a synthesis of studies on primary research that presents a particular topic by formulating specific and clear questions. Search methods are stated explicitly, studies that are to 
be reproducible reviewed, involvingcritical review in the selection of studies, and the results are communicated (Green, 2005).

The data that will be used in this study are research articles and reviewed ebooks (peerreviewed articles and books), published through online media in the last ten years (2005 - 2015),

\section{RESULTS AND DISCUSSION}

Learning requires efficiency of information processing, especially in activities related to education and clinical. There are several factors that influence the processing efficiency, including extrinsic factors (task and social relations) or intrinsic factors (self relations and spiritual relations). The effects of these factors are closely related to information processing structures. The review of this article focuses on how to minimize errors in information processing by increasing spiritual potential and cognition. Among them are external factors, in the form of theeffect of quantity and quality of information, the effectof instructions, and the learning programs. On the other hand, the intrinsic factors are in the form of the influence of previous information, individual strategies regarding the effects of performance, emphasizing the facts about human brain, even though the brain is not structured but has a function to overcome various limitations, as well as an introduction to spiritual values and cognitive values in education. Sudent must have the ability to quickly detect both cognition and spirituality (Wickens, 2000).

The extrinsics and intrinsics are important in terms of learning because of the strength of fasteffects and accurate performance to facilitate learning limitations. The effects of extrinsic factors are allowed to modify learning, while the effects of intrinsic are used in learning strategies (Wickens, 2000).

The influence of these factors is closely related to information processing structures in human. Related to extrinsic factors, first, the discussion is about the quantity and quality of information on cognition and spiritual basis; second, the influence of learning (instruction) and third, the influences of learning and the application of spiritual care programs. Whereas, for intrinsic factors, the discussion is about the influence of previous information; then, how each strategy influences performance and, furthermore, it is emphasized that although the human brain is not structured to function without error, humans are able to detect errors that are done very quickly; and (in most cases), humans can quickly correct errors before a worse failure occurs. The extrinsic factors and intrinsic factors are important factors in learning because (1) they greatly affect performance, both in terms of speed or accuracy, which facilitates or disrupts learning, (2) the influence of certain extrinsic factors can be greatly modified by learning and (3) spiritual intrinsic factors and certain cognitions are utilized for innovative learning strategies (Wickens, 2000).

References from research about development of teaching with spiritual care affect cognitive competence and student behavior. The result gives positive effects for teachers in applying spiritual care and helps students to learn more systematically in carrying out the curriculum in education (Van Leeuwen, et al., 2008). Other studies of spirituality that teachers have helped to identify factors in effective learning which are required for students to apply spiritual care (Taylor, et al., 2008).

Exploration of teacher's understanding of spirituality and how they prepare students to recognize spiritual cues and learn to assess their respective spiritual care. Systematic teaching to prepare them spiritually is an important part of the education process. However, some role models for spiritual care are seen in clinical practice, and research in education is limited on discussing student competencies to recognize personal spirituality or how teachers can facilitate this process. The results prepare students to recognize and act on spiritual instructions. Making spiritual judgments and interventions more visible and explicit throughout nursing programs, both in classrooms and clinical settings, will facilitate the maturation of students as they learn to integrate theoretical thinking. Information processing and spiritual care can help students overcome their vulnerabilities and to maintain ethical problems 
and improve self-integrity (Cone \& Giske, 2012).

Information processing combined with essential spiritual care included findings that thematic analysis identified three themes: (a) students' perceptions of spirituality, (b) spiritual care, and (c) factors that influenced spiritual care in teaching practices. Teaching is considered to play an integral role in education, enabling factors need to be handled systematically both in the education arena (Tiew \& Drury, 2012). The research describes a high-duration simulation education program that is designed to familiarize educators and learners in carrying out spiritual care to improve the level of the learning process in receiving and giving learning material in class and in the classroom (Rodriguez et al., 2012). Spiritual care also helps in rehabilitation. Spirituality is presented as a potential source for people with disabilities. Spiritual care combined with information processing is very helpful in the maintenance of rehabilitation professionals in education (Byrd, 2008).

Findings from the teaching program of spirituality for students with different spiritual needs. Further research is needed, using a rigorous approach, examining the benefits of teaching. An analytical approach to the need for spiritual education is also needed. The concerning problem for educators is the definition and understanding of spirituality, assessment and how the best way for teaching this to students requires an in-depth understanding of spiritual needs and spiritual habituation in the enhancement of cognition in accordance with information processing (Timmins \& Neill, 2013).

Positive feedback from studentshighlights the importance of teaching spiritual care in the education curriculum for the benefit of teachers and learners (Baldacchino, 2007).

The link with the new finding information processing research is that errors (mistakes) are strongly related to various levels of information processing, such as: prevention, detection, inhibition, correction, and if this mechanism finally fails, then adjusting strategic behavior occurs after a mistake is made. It is also hoped that in certain situations, if the instruction is sufficiently correct or learning is given for a long period of time, the errors that occur will be fully eliminated. Therefore,consistent attitudes towards cognitive and spirituality are need to decrease the errors (Wickens, 2000).

Furthermore, the information processing approach differs from traditional human views. Refusing the old notion that humans are passive recipients of information, on the contrary humans are regarded as active, dynamic systems, have flexibility in handling and transforming incoming information. Meanwhile, there are some opinions that limit information processing only two fields, memory and attention. No adaptive system can function without this ability. Therefore, reviewing current theoretical models and selected empirical findings will help understanding how humans remember information. This model is important and practical especially about human factors, is able to conclude a detailed discussion of mental workload, research on human factors that are closely related to attention in education world (Kantowitz \& Sorkin, 1983).

The ability to remember information is an important and vital element in the processing of human information. Even a simple adaptive system cannot function without memory and the human system is a complex system. Human memory is a limited resource and people must be careful not to overload memory. When there are emergency situations occurring at the same time as memory systems approach human peak loads, there is a failure of human memory and this is the least expected. Therefore, it is a challenge when designing a system that does not burden memory. (Passer \& Smith, 2007).

Attention is the concentration of the mind, in a clear and gambling form, against a number of simultaneous objects or groups of thoughts. Centralization (facalization) of awareness is the essence of attention. Attention implies the dedication of other objects so that we can effectively handle certain objects. When we talk about "attention" from the perspective of contemporary cognitive psychologists, we are referring to a cognitive process that selects 
important information from the world around us (through the senses), so that our brains are excessively filled with unlimited information. In addition, it is also mentioned that attention is the concentration of mental effort on sensory events or mental events (Passer \& Smith, 2007).

Research on attention covers five main aspects: attenuating and processing capacity, level of stimulation, attention control, awareness, and cognitive neuroscience. A large number of contemporary ideas about attention focus on the premise that there are infinite cues around us, all the time. Our neurological capacity is too limited to detect millions of external stimuli, and even if all these stimuli can be detected, our brain will not be able to process millions of these stimuli, because the information processing capacity is limited. The human sensory system, as well as other types of communication channels, functions well when the amount of information processing is within the range of system capabilities, whereas the system does not work well if it is overloaded. Donald Broadbent (in Solso. Maclin. \& Maclin, 2008), a British psychologist suggested the idea that attention is the result of the limited capacity of information processing systems. The main idea in this theory is that the world is composed of sensations in numbers that far exceed the amount of sensation that can be processed by the observer's (human) perceptual and cognitive abilities (Passer \& Smith, 2007).

In order to process the information that is so flooded, humans selectively select only a number of signals and ignore other stimuli. Our daily experience teaches us that we pay attention to a number of cues from our environment more often than other cues, and the signals we notice are generally further by the cognitive system, while neglected cues do not undergo further processing. The mechanism focuses on certain stimuli and ignores other stimuli.

\section{CONCLUSION}

The alternative innovative teaching that can be achieved most in student preparation is an increase in awareness of the depth of human nature, enthusiasm and interaction. In teaching, there are some aspects of humanity that reject explanation and structure. Formalization and formulation are not desirable. It is still a consideration whether it is wise to educate future students from their creative abilities with a structured approach to assessment and consistency in spiritual care so that they are automatically able to increase competence in the form of increasing cognition as the core of education (Kelly, 2014).

\section{REFERENCES}

Baldacchino. (2008). Teaching on the spiritual dimension in care: The perceived impact on undergraduate nursing students. Nurse Education Today. 28, 501-512

Bhinnety, M. (2008). Struktur dan Proses Memori dalam Buletin Psikologi Edisi Khusus Memori. Jogjakarta: Fakultas Psikologi UGM.

Byrd, K. (2008). Spiritual Care Matters.Journal of Religion, Disability \& Health Publication. 3:1, 3-13, DOI: $10.1300 / J 095 v 03 n 01 \_02$

Cone, P.H \&Giske, T. (2012) Teaching spiritual care - a grounded theory study among undergraduate nursing educators.Journal of Clinical Nursing, Doi: 10.1111/j.1365-2702.2012.04203.x.

Kantowitz, B.H and Sorkin, R.D. (1983). Human FactorsUnderstanding People-System Relationsips. New York : John Wiley \& Sons

Kelly, J. (2014). Commentary on Cone P.H and Giske : Teaching spiritual care - a grounded theory study among nursing educators. Journal of Clinical Nursing, 1951-1960.

Passer MW, Smith RE. (2007). Psychology; the Science of Mind and Behavior. New York: McGraw-Hill

Rodriguez, E. Johnson., G.S., Culbertson., T. \& Grant., W. (2012). An educational program for spiritual care providers on end of life care in the critical care setting. Journal of Interprofessional Care, 2011, 25: 375-377

Taylor, E.J., Bahjri, K., Anton, T., Peterson, F. (2008). Issues In Nurse Education :Efficacy of a self-study programme to teach spiritual care. Journal of Clinical Nursing, 18, 1131-1140.

Tiew, L.H \& Drury, V. (2012). Singapore Nursing Students' Perceptions and Attitudes About Spirituality and Spiritual Care in Practice A Qualitative. Journal of Holistic Nursing American. 3 (3), 160-169. Doi 10.1177/089801011143594.

Timmer,B.,Bleicardt,G.,\&Rief.,W.2006.Importanceofpsyc hoterapymotivationinpatientswithsomatizationsyndrom e.JournalofP sychotherapyResearch,16 (3), 348-356.

Timmins, F. \& Neill., F. (2013). Teaching nursing students about spiritual care e A review of the literature. Nurse Education in Practice.1-7. 
Van Leeuwen, R., Tiesinga., L.J., Midel, B., Post., D., Jochemsen. (2008). The effectiveness of an educational programme for nursing students on developing competence in the provision of spiritual care. Journal of Clinical Nursing, 17, 2768-2781.

Walker, L.O. \& Avant, K.C. (2011) Strategies for Theory Construction in Nursing.Prentice Hall, Englewood Cliffs, NJ.

Wickens, C.D. \& Hollands, J.G. 2000. Engineering Ps 